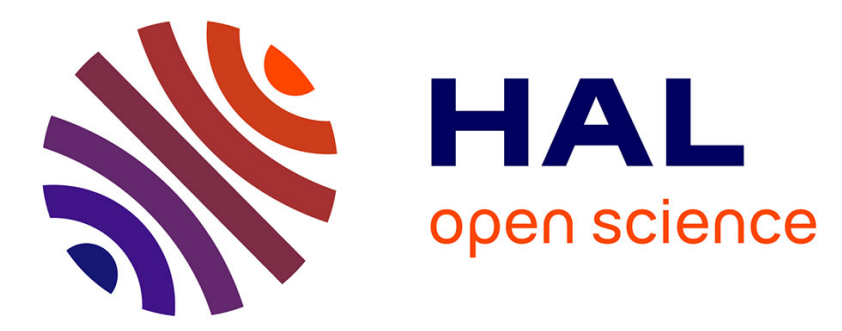

\title{
The NRAMP6 metal transporter contributes to cadmium toxicity
}

Rémy Cailliatte, Bruno Lapeyre, Jean-François Briat, Stéphane Mari, Catherine Curie

\section{To cite this version:}

Rémy Cailliatte, Bruno Lapeyre, Jean-François Briat, Stéphane Mari, Catherine Curie. The NRAMP6 metal transporter contributes to cadmium toxicity. Biochemical Journal, 2009, 422 (2), pp.217-228. 10.1042/BJ20090655 . hal-00479190

\section{HAL Id: hal-00479190 https://hal.science/hal-00479190}

Submitted on 30 Apr 2010

HAL is a multi-disciplinary open access archive for the deposit and dissemination of scientific research documents, whether they are published or not. The documents may come from teaching and research institutions in France or abroad, or from public or private research centers.
L'archive ouverte pluridisciplinaire HAL, est destinée au dépôt et à la diffusion de documents scientifiques de niveau recherche, publiés ou non, émanant des établissements d'enseignement et de recherche français ou étrangers, des laboratoires publics ou privés. 


\title{
The NRAMP6 Metal Transporter Contributes to Cadmium Toxicity
}

\author{
Rémy CAILLIATTE*†, Bruno LAPEYREł, Jean-François BRIAT*, Stéphane \\ MARI* and Catherine CURIE*1
}

\footnotetext{
*Laboratoire de Biochimie et Physiologie Moléculaire des Plantes CNRS UMR5004, Institut de Biologie Intégrative des Plantes, F-34060 Montpellier, France †AgroParisTech ENGREF, F-75732 Paris, France ¥Centre de Recherche de Biochimie Macromoléculaire du CNRS UMR 5237, F-34293 Montpellier, France

${ }^{1}$ To whom correspondence should be addressed: Catherine Curie, Tél: +334 996131 40, Fax: +334 675257 37, -mail: curie@supagro.inra.fr
}

Short title: NRAMP6 and cadmium toxicity 


\title{
SYNOPSIS
}

Natural Resistance Associated Macrophage Protein (NRAMP) homologues are evolutionarily conserved divalent metal transporters. In Arabidopsis, AtNRAMP3 and AtNRAMP4 play a key role in iron nutrition of the germinating plantlet by remobilizing vacuolar Fe stores. Here we describe the molecular and physiological characterization of AtNRAMP6. AtNRAMP6 is predominantly expressed in the dry seed embryo and to a lesser extent in aerial parts. Its promoter activity is found diffusely distributed in cotyledons and hypocotyls as well as in the vascular tissue region of leaf and flower. We show that AtNRAMP6 transcript coexists with a partially spliced isoform in all tested shoot cell types. When expressed in yeast, AtNRAMP6, but not its misspliced derivative, increased sensitivity to cadmium without affecting $\mathrm{Cd}$ content in the cell. Likewise, Arabidopsis transgenic plants overexpressing AtNRAMP6 were hypersensitive to $\mathrm{Cd}$ although plant $\mathrm{Cd}$ content remained unchanged. Consistently, a null allele of AtNRAMP6, named nramp6-1, was more tolerant to Cd toxicity, a phenotype that was reverted by expressing AtNRAMP6 in the mutant background. We used an AtNRAMP6: HA fusion, shown to be functional in yeast, to demonstrate through immunoblot analysis of membrane fractions and immunofluorescence localization that, in yeast cells, AtNRAMP6 is targeted to a vesicularshaped endomembrane compartment distinct from the vacuole or mitochondria. We therefore propose that AtNRAMP6 functions as an intracellular metal transporter, whose presence, when modified, is likely to affect distribution/availability of $\mathrm{Cd}$ within the cell.

Keywords: NRAMP, Transport, Cadmium, Toxicity, Heavy metal, Endomembrane

\begin{abstract}
Abbreviations used: NRAMP: Natural Resistance Associated Macrophage Protein. DCT1: Divalent Cation Transporter 1. DMT1: Divalent Metal Transporter 1. MntH: Mn Transporter H. DAPI: 4',6' Di Amidino-2-Phenyl Indole.
\end{abstract}




\section{INTRODUCTION}

Cadmium is an environmental pollutant with high toxicity to plants and animals. Despite the existence of a cadmium-containing carbonic anhydrase in a marine diatom [1], $\mathrm{Cd}$ is commonly considered as a nonessential transition metal. $\mathrm{Cd}$ is classified as a human carcinogen that affects many cellular processes including cell cycle, cell proliferation, and DNA repair [2]. Cd also disrupts homeostasis of essential metals, which it displaces in metal-binding proteins such as transcription factors or enzymes. Although $\mathrm{Cd}^{2+}$ is not a redox-active metal, it indirectly induces oxidative stress. In plants, cadmium affects root growth and biomass production by inhibiting photosynthesis, respiration and mineral uptake and by disturbing the plant water status $[3,4]$. The presence of $\mathrm{Cd}$ in plants and more particularly its translocation to edible parts represents its main entry route into the food chain. Knowledge of the molecular events by which $\mathrm{Cd}$ is taken up by cells or detoxified therefore, could provide potential targets to reduce its toxicity.

$\mathrm{Cd}$ is supposed to enter the plant as an opportunistic hitchhiker using transporters of essential metals. IRT1, a metal transporter essential for root iron uptake in response to iron deficiency, is also known to accept $\mathrm{Cd}$ as a substrate [5, 6]. As a result, the Arabidopsis irt1 loss-of-function mutant fails to accumulate heavy metals, including $\mathrm{Cd}$, when grown in iron-limited conditions [7]. Furthermore a mammalian homolog of IRT1, ZIP8, was shown in mouse to be implicated in cadmium-induced toxicity in the testis [8].

Once cadmium has entered the cells, plants use various strategies to cope with its toxicity. One such strategy involves the chelation of cadmium by a family of thiol-containing ligands such as glutathione and its derivative phytochelatins (PC) [9]. Genetic studies have confirmed that PCdeficient mutants are hypersensitive to $\mathrm{Cd}[10]$. Another strategy consists in transporting cadmium out of the cell or sequestering it into organelles, thereby removing it from the cytosol. A number of transporter families contribute to cadmium resistance. The yeast ATP-binding cassette (ABC) transporters, ScYCF1 and SpHMT1, sequester heavy metals by pumping GSHconjugated cadmium and PC-conjugated cadmium, respectively into the vacuole $[11,12]$. No similar function has been found yet among plant $\mathrm{ABC}$ transporter homologues but the $\mathrm{ABC}$ transporter AtPDR8 was recently shown to mediate the extrusion of $\mathrm{Cd}$ out of the plasma membrane of root epidermal cells [13]. Detoxification of cadmium is also achieved by members of the heavy metal-transporting P-type ATPases (HMA) subfamily [14]. HMA4 is a $\mathrm{Zn} / \mathrm{Cd}$ transporter that confers plant tolerance to $\mathrm{Cd}$ by loading it into the xylem, thus increasing translocation to the shoot where it might have less damaging effects $[15,16]$.

Another family of metal transporters potentially involved in the mobilization of cadmium is the natural resistance-associated macrophage protein (NRAMP) family. First identified in mammals, the NRAMP/DCT1/DMT1 proteins are evolutionarily conserved, with homologues in bacteria, algae, plants and animals. Measurements of transport activity conferred by heterologous expression in Xenopus laevis oocytes have revealed that NRAMP transporters accept a broad range of substrates including $\mathrm{Fe}^{2+}, \mathrm{Zn}^{2+}, \mathrm{Mn}^{2+}, \mathrm{Co}^{2+}, \mathrm{Cd}^{2+}, \mathrm{Cu}^{2+}, \mathrm{Ni}^{2+}$ and $\mathrm{Pb}^{2+}$ and that this active transport is coupled with a proton [17]. However, the physiological role of NRAMP is mainly recognized for iron and to a lesser extent for manganese. Nramp1 is specific to macrophages where it has been shown to confer resistance to pathogen invasion probably by modulating metal ion content in the phagosome [18]. Nramp2 is thought to be the main transporter for the absorption of dietary iron at the brush-border membrane of the mammalian intestine [19] and to contribute to $\mathrm{Fe}^{2+}$ and $\mathrm{Mn}^{2+}$ recycling from the transferrin [20]. 
Members of the NRAMP family have been characterized in many plants species including rice, soybean and Thlaspi as well as in the green algae Chlamydomonas [21-27]. Through complementation of yeast metal transport mutants, they have been shown to function as metal ions transporters, however very few of them have been assigned a physiological function. The soybean GmDmt1, located on the peribacteroid membrane of root nodules and shown to mediate ferrous iron uptake in yeast, was proposed to provide iron to developing rhizobia [23]. In the $\mathrm{Ni}$ hyperaccumulator Thlaspi japonicum, TjNRAMP4 specifically transports Ni when expressed in yeast and might therefore contribute to Ni hyperaccumulation in the plant [24]. In Arabidopsis, 6 genes AtNRAMP1-6 encode NRAMP proteins. The most closely related members, AtNRAMP3 and AtNRAMP4, are metal transporters with a broad range of substrate specificity including $\mathrm{Fe}$, $\mathrm{Mn}, \mathrm{Cd}$ and $\mathrm{Zn}$, as determined by functional complementation of yeast mutants [26, 28-30]. AtNRAMP3 and AtNRAMP4 are tonoplastic proteins with redundant functions. In iron-limiting growth conditions, germination of the double nramp 3 nramp 4 mutant is arrested. Mutant seeds were shown to be unable to retrieve iron from vacuolar globoids upon germination, indicating that AtNRAMP3 and AtNRAMP4 function in the mobilization of iron from vacuolar stores to feed the developing plant [29]. The role of AtNRAMP1 in planta has not yet been deciphered. However, AtNRAMP1 expression in yeast was shown to rescue the growth defect of iron and manganese transport defective mutants $[22,26]$. In addition, overexpressing AtNRAMP1 in Arabidopsis yielded plants with increased tolerance to excess iron, suggesting a contribution of AtNRAMP1 to plant iron homeostasis [22].

In this paper, we identified AtNRAMP6 as an intracellular cadmium transporter. We show that AtNRAMP6 confers cadmium hypersensitivity when expressed in yeast or when overexpressed in Arabidopsis, without affecting yeast or plant cadmium content. Conversely, knocking out AtNRAMP6 resulted in Arabidopsis plants with increased tolerance to cadmium. AtNRAMP6 protein accumulation was observed in a yeast intracellular membrane. The data presented here suggest that AtNRAMP6 is a cadmium transporter that functions inside the cell either by mobilizing $\mathrm{Cd}$ from its storage compartment or by taking up $\mathrm{Cd}$ into a cellular compartment where it is toxic.

\section{EXPERIMENTAL}

\section{Plasmids}

For the reconstruction of AtNRAMP6 cDNA, an AtNRAMP6 cDNA retaining the intron 6 (I6) of the gene was amplified from reverse transcribed total Arabidopsis RNA and cloned into the pGEM®-T Easy vector (gift of Sébastien Thomine, Gif-sur-Yvette, France). To eliminate the I6 $77 \mathrm{bp}$ sequence, the $194 \mathrm{bp}$ ScaI-XhoI fragment surrounding I6 was replaced by a $117 \mathrm{bp}$ fragment corresponding to the spliced RNA. The $117 \mathrm{bp}$ intron-less fragment was generated by PCR using I6 containing-AtNRAMP6 cDNA as a template, a forward primer encompassing the ScaI site in exon 5 and a reverse primer encompassing the E6-E7 junction up to the XhoI site located close to the 5' end of exon 7. The resulting clone was sequenced (see the sequence surrounding the E6-E7 junction in Fig1). The 35S-AtNRAMP6 construct for overexpression in plants was obtained by subcloning the AtNRAMP6 cDNA KpnI - BamHI into the pCHF3 vector [31] in translational fusion with the CaMV $35 S$ promoter. For expression in yeast, AtNRAMP6 cDNA sequences, containing the intron 6 or without it, were subcloned as a SalI- BamHI 
fragment into the XhoI and BamHI sites of the pDR195 [32] yeast expression vector. The HA epitope-tagged AtNRAMP6 construct was obtained by cloning an amplified 2 X HA fragment (primers TagHA F and TagHA R) in the BamHI site located in 3' of AtNRAMP6 cDNA in the pCHF3-AtNRAMP6 plasmid, and subsequently subcloning the XhoI-BamHI [AtNRAMP6::HA] cassette thus obtained in the XhoI and BamHI sites of the pDR195 vector. To generate a fusion between AtNRAMP6 promoter and the B-Glucuronidase (GUS), a $1.45 \mathrm{~kb}$ fragment of AtNRAMP6 promoter sequence located upstream the translation initiation codon was amplified by PCR on BAC T24D18 using the forward primer OCC51 and the reverse primer OCC52 which contain a HindIII and a NcoI site respectively. The resulting promoter fragment was cloned in translational fusion with the uidA gene in the pBKS-GUS vector [33] digested with HindIII and NcoI. The [AtNRAMP6 promoter-GUS] cassette thus obtained was then subcloned into the binary vector pBIN19 [34] digested with the same enzymes to generate the plasmid pBIN19/AtNRAMP6-GUS.

\section{Plant growth conditions, genotypes and transformation}

Arabidopsis seedlings were grown on plates containing 1/2 MS [35]. When indicated, $\mathrm{CdSO}_{4}$ was added into the medium from a 10mM stock solution. The Arabidopsis GABI-Kat line ID 550D06 contains a T-DNA inserted 1940 bp downstream the translation initiation codon of AtNRAMP6 in the intron 9. Homozygous plants were screened by PCR using primers NR6S and either NR6AS or GKLB (T-DNA left border). GKLB amplified a fragment with both NR6S and NR6AS primers, indicating that at least two T-DNAs are inserted in inverted orientation, with their left border towards AtNRAMP6 gene sequences (see Figure 5). Sequencing of the T-DNA/gene junctions reveals a deletion of $19 \mathrm{bp}$ of AtNRAMP 6 sequence at the insertion site. Transformation of A. thaliana ecotype Col-0, either wild-type or nramp6-1 mutant, was performed using the GV301 strain of Agrobacterium tumefaciens following the floral deep method [36]. Transformed $\mathrm{T} 1$ plants were selected on kanamycin.

\section{Histochemical analysis of GUS activity}

Eight independent transgenic Arabidopsis lines were analyzed for GUS activity. Plants were grown on plates containing iron-replete medium for 12 days. Plantlets were harvested in phosphate buffer $\left(50 \mathrm{mM} \mathrm{NaPO}_{4}, 0.05 \%\right.$ Triton $\left.\mathrm{X}-100, \mathrm{pH} 7.2\right)$ and pre-fixed in $4 \% \mathrm{v} / \mathrm{v}$ formaldehyde in phosphate buffer by vacuum infiltration for $45 \mathrm{~min}$. Samples were washed 3 times in phosphate buffer prior to be vacuum infiltrated for $15 \mathrm{~min}$ then soaked overnight at $37^{\circ} \mathrm{C}$ in a solution containing $1 \mathrm{mM} \mathrm{X}$-Gluc (5-bromo-4-chloro-3-indolyl- $\beta$-D-glucuronide) in GUS buffer $(50 \mathrm{mM} \mathrm{NaPO} 4,0.5 \mathrm{mM}$ ferrocyanide, $0.5 \mathrm{mM}$ ferricyanide, $0.05 \%$ Triton $\mathrm{X}-100, \mathrm{pH}$ 7.2). Samples were cleared by successive steps of increasing ethanol concentration before observation.

\section{Expression analyses}

Total RNA was extracted using the TRIZOL reagent (Invitrogen, San Diego) as described by the manufacturer. A DNase (Promega, Madison, WI, USA) treatment was performed to avoid genomic DNA contamination. The integrity of DNA-free RNA was verified on agarose gel electrophoresis and equal amounts $(3 \mu \mathrm{g})$ were used for reverse transcription (MMLV-RT, 
Promega) with anchored oligo $\left(\mathrm{dT}_{23}\right)$. Real-time PCR was performed using the LightCycler ${ }^{\circledR}$ FastStart DNA Master ${ }^{\text {PLUS }}$ SYBER GREEN I (Roche, http://www.roche.com) using the NRAMP6 specific (forward GAGTCCTCGTCCACACATTTCC, reverse TTTAAGTCTCCTATAACCGCTACTC) primers. Relative transcripts levels were calculated relative to the transcript amount of the constitutively expressed Clathrin gene (At4g24550) (forward AGCATACACTGCGTGCAAAG, reverse TCGCCTGTGTCACATATCTC). NRAMP6 cDNA polymorphism: cDNA isoforms were amplified from total RNA extracts using NR6 I6F forward primer and E7 GCGATCAAGAACTCGAGC reverse primer. Relative transcripts levels were calculated relative to the transcript amount of the constitutively expressed actin gene (At3g18780) (forward GGTAACATTGTGCTCAGTGGTGG, reverse AACGACCTTAATCTTCATGCTGC).

\section{Yeast strains and growth conditions}

W303 (ade2/ade2 his3/his3 leu2/leu2 trp1/trp1 ura3/ura3) and $\Delta$ smf1 (MATa/MATa ade2/ade2 his3/his3 leu2/leu2 trp1/trp1 ura3/ura3 smf1::URA3ura3::TRP1). Cultures were performed in YNB $+2 \%$ D-glucose - Uracyl. For complementation of $\Delta \mathrm{smf1}$, the medium was supplemented or not with 5mM EGTA. Cadmium-induced growth inhibition was tested in the W303 wild-type strain as follows: 4 independent clones containing either pDR195-NRAMP6 or the empty pDR195 vector were grown overnight in liquid YNB. These precultures were used to inoculate 2 $\mathrm{ml}$ cultures containing increasing concentrations of $\mathrm{CdSO}_{4}(0 ; 2 ; 5 ; 10 ; 20 ; 40 \mu \mathrm{M})$ at a $\mathrm{D}_{600}=$ 0.02 and grown overnight to reach the stationary phase. Growth inhibition was estimated by measuring the final $\mathrm{D}_{600}$ of the cultures.

\section{Yeast protein extract}

Total protein extracts were prepared from yeast cultures grown until a $\mathrm{D}_{600}=1.5$ in YNB. Cells were harvested, washed with water, resuspended in extraction buffer $\left(50 \mathrm{mM} \mathrm{KH}_{2} \mathrm{PO}_{4} \mathrm{pH} 7.8\right.$, $1 \mathrm{mM}$ EDTA, $0.1 \%$ Triton X-100). Protein lysates were obtained using glass beads in the presence of protease inhibitors $(100 \mu \mathrm{g} / \mathrm{ml}$ phenylmethylsulfonyl fluoride, $1 \mu \mathrm{g} / \mathrm{ml}$ pepstatin $\mathrm{A}$, $1 \mu \mathrm{g} / \mathrm{ml}$ leupeptin) and vortexing $15 \times 20 \mathrm{~s}$, with $30 \mathrm{~s}$ on ice between pulses. The cell debris were pelleted by centrifuging $5 \mathrm{~min}$ at $2500 \mathrm{x}$ g at $4^{\circ} \mathrm{C}$. The resulting supernatant represented the total protein extract. Plasma membrane proteins were prepared from W303 yeast strain transformed either with the empty pDR195 vector or pDR195-AtNRAMP6-HA and grown for 2 days in 2 liters YNB -Ura containing $2 \%$ glucose at $30^{\circ} \mathrm{C}$ according to [37]. Protein content was determined according to Bradford [38]. Proteins were denatured for $10 \mathrm{~min}$ at $65^{\circ} \mathrm{C}$ and loaded onto SDSPAGE for immunoblotting according to standard procedures.

\section{Immunoblot detection}

The following antibodies were used: mouse Anti-HA (ZYMED Laboratories, Carlsbad, CA) diluted 1:4000, mouse Anti-yeast V-ATPase diluted 1:2000 as a yeast vacuolar marker, mouse Anti-yeast cox $2 p$ diluted 1:500 as a mitochondrial marker (Molecular probes Inc., PO Box 22010, Eugene, OR 97402-0469), mouse Anti-yeast Pmalp diluted 1:10000 as a plasma membrane marker (Abcam plc Cambridge, CB4 0WN, UK) and an Anti-mouse conjugated to 
alkaline phosphatase (Invitrogen) diluted 1:10000. Membranes were washed three times, first with blocking buffer, secondly with PBS $1 \mathrm{X}$ and finally with Tris $\mathrm{HCl} 20 \mathrm{mM}, \mathrm{MgCl}_{2} 1 \mathrm{mM}$ for 5 min. Membranes were then incubated $5 \mathrm{~min}$ in the presence of "Aurora Chemiluminescence Substrate Solution" (Millipore Corporation, Bellerica, MA 01821, USA). Chemiluminescence was revealed on a LAS 3000 Imager (Fujifilm).

\section{Immunofluorescence detection in yeast}

Cells were treated according to [39] using a mouse monoclonal anti-HA (Sigma) as a primary antibody and a goat anti-mouse antibody coupled to Alexa 546 as a secondary antibody (Molecular Probes). Cells were examined using a Zeiss Axioplan2 confocal microscope equipped with a LSM 510 META head.

\section{Elemental analyses}

Yeast cultures were grown in SD medium supplemented with $2 \mu \mathrm{MCdSO}_{4}$ to a $\mathrm{D}_{600}=1.5$. Cells were harvested, washed 3 times with water. For mineralization, pelleted yeast cells or harvested plant parts were desiccated for two days at $80^{\circ} \mathrm{C}$. Samples were boiled for 1 to $3 \mathrm{~h}$ at $200{ }^{\circ} \mathrm{C}$ in 1 $\mathrm{ml}$ of $69 \% \mathrm{HNO}_{3}$ in a pyrex tube. Cadmium concentration in the samples was measured by atomic absorption spectrometry (SpectrAA220 Fast sequential, Varian, Australia).

\section{RESULTS}

\section{Cloning of a functional AtNRAMP6 cDNA}

The Arabidopsis annotated genome indicates the existence of six members of the NRAMP protein family, among which AtNRAMP1 and AtNRAMP6 proteins form a separate cluster and share $81.5 \%$ identity (Figure 1A). AtNRAMP6 polypeptide contains 12 putative membranespanning domains, a consensus transport motif common to NRAMP homologues and located in the cytoplasmic loop between transmembrane domains 8 and 9, as well as 1 putative $N$-linked glycosylation site (Figure 1B).

Attempts to isolate AtNRAMP6 cDNA led clones retaining part or all of the sixth intron of the gene. Figure 2A shows examples of mis-spliced AtNRAMP6 clones around the intron 6, obtained independently either by RT-PCR on total RNA extracted from whole plantlets or by the Riken Bioresource Center in its Arabidopsis full-length cDNA cloning program (http://www.brc.riken.jp/lab/epd/Eng/catalog/RAFL.shtml). Retention of the full intron 6, which is most frequently seen, introduces a stop codon 36 nucleotides downstream the E6-I6 junction (labeled with an asterisk in Figure 1A), resulting in the addition of 12 amino acids and in premature translation termination. Based on the amino acid sequence homology between AtNRAMP6 and AtNRAMP1 as well as on the known consensus sequences of splice junctions, we have re-constructed a fully spliced AtNRAMP6 cDNA (see Material and Methods).

To check whether plants produce the two mRNA species, the intron 6-containing and the intron-less forms, we performed RT-PCR using primers encompassing intron 6 (Figure 2B). The Riken cDNA (RAFL05-14-K06 clone) and the fully spliced, re-constructed cDNA were used as control templates. Both root- and shoot-extracted RNA produced two amplified fragments, whose 
sizes corresponded to the fully spliced species and to the intron-retaining species, respectively (Figure 2C, lanes a and b). Moreover, the identity of the two amplified fragments was verified by sequencing. Both the misspliced and the spliced forms of AtNRAMP6 mRNA therefore, coexist in vivo. Since it is well known that regulation of gene expression can occur at the level of intron retention, we investigated the possibility that AtNRAMP6 is differentially expressed in the various organs through the retention of its intron 6 . Indeed, semi-quantitative RT-PCR analysis showed a variation of the ratio of spliced to misspliced forms between the organs (Figure 2C, lanes c to i). Two organs, open flowers and siliques, showed the highest concentration of spliced AtNRAMP6 cDNA. Nevertheless, all tissues contained a significant amount of the misspliced form.

\section{AtNRAMP6 mediates cadmium toxicity in yeast}

All of the NRAMP homologues described have been shown to rescue the phenotype of Saccharomyces cerevisiae metal transport mutants. Among the Arabidopsis members, AtNRAMP1, AtNRAMP3 and AtNRAMP4 were shown to complement $\Delta$ fet $3 \Delta f e t 4$ and $\Delta s m f 1$ strains, defective in Fe and Mn uptake respectively [22, 26]. AtNRAMP4 was additionally shown to complement the phenotype of $\Delta z r t 1 \Delta z r t 2$, a $\mathrm{Zn}$ uptake-defective mutant [28]. In the case of AtNRAMP6 however, its expression as a fully spliced cDNA or as a cDNA retaining the intron 6 failed to restore growth of any of the yeast metal transport mutants (data not shown).

In addition to essential metals, NRAMP homologues have been shown to be involved in the transport of toxic metals such as cadmium or nickel $[24,26]$. To reveal such a function for AtNRAMP6, wild-type yeast cells expressing the AtNRAMP6 reconstructed cDNA were grown in standard YNB medium (Figure 3A) or in the presence of $25 \mu \mathrm{M} \mathrm{CdSO}_{4}$ in the culture medium (Fig 3B). Although AtNRAMP6 did not impair yeast growth in standard medium, its presence increased $\mathrm{Cd}$-induced growth inhibition (Figure $3 \mathrm{~B}$ ). When yeast was transformed with the intron-containing version of AtNRAMP $6 \mathrm{cDNA}$, growth inhibition was not observed (Figure 3B). We concluded that, at least in yeast, only the fully spliced form of AtNRAMP6 cDNA is functional.

To quantify AtNRAMP6-induced toxicity, we performed a growth inhibition experiment in liquid medium containing increasing concentrations of $\mathrm{Cd}$. The concentration-response curves indicated an $\mathrm{IC}_{50}(\mathrm{Cd}$ concentration necessary to reach $50 \%$ growth inhibition) of 1.0 and 1.7 for pDR195-AtNRAMP6 and pDR195 respectively, with a maximum difference of growth inhibition reaching 4-fold at $5 \mu \mathrm{M}$ Cd (Figure 3C). Therefore, when expressed in yeast, AtNRAMP6 confers higher sensitivity to external cadmium concentration.

\section{Expression pattern of AtNRAMP6}

Consistent with reported expression levels in public microarrays databases (http://bar.utoronto.ca/efp/cgi-bin/efpWeb.cgi, At1g15960), AtNRAMP6 transcript, as measured by real time RT-PCR, was found to accumulate predominantly in seeds and levels decreased rapidly upon germination (Figure 4A). AtNRAMP6 expression was also detected in shoot tissues, although to a lesser extent, but not in roots (Figure 4B,C). Accumulation of AtNRAMP6 transcripts was detected in leaves, senescing leaves, floral buds, opened flowers, siliques and silique peduncles (Fig 4C). 
To investigate the tissue specificity of AtNRAMP6, transgenic plants expressing the uidA gene, encoding the B-Glucuronidase (GUS), under the control of a $1.45 \mathrm{~kb}$-long fragment of AtNRAMP6 promoter were produced. Histochemical staining of GUS activity (Figure 4D) confirmed that the AtNRAMP6 promoter is active in dry seeds where it is diffusely distributed in cotyledons and hypocotyls of the embryo (a). Staining was also detected in the vascular bundles of shoot tissues including cotyledons (b), young leaves (d), sepals and petals (c), at the top of the flower stem and in the style (c). Developing siliques showed GUS activity in the peduncle (e), as well as in the septum and the funiculi (f).

Neither transcripts accumulation nor AtNRAMP6 promoter-driven GUS activity was modified upon treatments by deficiency or excess of Fe, Mn, or $\mathrm{Zn}$ or by $\mathrm{Cd}$ supply (data not shown).

\section{The namp6-1 mutant is tolerant to cadmium toxicity}

We next used reverse genetics to study the physiological function of AtNRAMP6. An Arabidopsis line (GK Line ID: 550D06) containing 2 inverted repeated copies of T-DNA inserted in the intron 9 of the AtNRAMP6 gene (Figure 5A) was identified in the GABI-Kat library of mutants (http://www.mpiz-koeln.mpg.de). AtNRAMP6 transcripts were undetectable in the nramp6-1 line, indicating that this mutant is a null allele of AtNRAMP6 (Figure 5B).

nramp6-1 plants had no apparent phenotype; however, in order to investigate whether the lack of AtNRAMP6 disturbed plant metal homeostasis, nramp6-1 seeds were germinated in vitro on medium either lacking $\mathrm{Fe}, \mathrm{Mn}, \mathrm{Zn}$ or $\mathrm{Cu}$, or containing excess amounts of these metals. In response to these treatments, growth of Arabidopsis wild-type and nramp6-1 mutant plants was not differentially affected, indicating that knocking out AtNRAMP6 does not impair the ability of the plant to maintain $\mathrm{Fe}, \mathrm{Mn}, \mathrm{Zn}$ or $\mathrm{Cu}$ homeostasis (Supplementary Figure S1). Elemental analysis of whole seed, root or shoot tissues, performed using Atomic Absorption Spectrometry (AAS), did not reveal any change in total metal content in the nramp6-1 mutant.

Because we observed that the expression of AtNRAMP6 in yeast mediates hypersensitivity to $\mathrm{Cd}$, we tested the possibility that nramp6-1 might be resistant to a $\mathrm{Cd}$ treatment. Four week-old WT and nramp6-1 plants were supplied with $50 \mu \mathrm{M} \mathrm{CdSO}_{4}$ during 10 days. While WT plants developed toxicity symptoms such as yellow leaves, nramp6-1 leaves remained mostly green during the treatment (Figure $5 \mathrm{C}$ ), indicating a better tolerance of the nramp6-1 mutant to $\mathrm{Cd}$ toxicity. Transformation of nramp6-1 with the AtNRAMP6 cDNA expressed under the control of the strong ubiquitous Cauliflower Mosaic Virus (CaMV) 35S promoter restored Cd sensitivity of the mutant (Supplementary Figure S2). This result suggested that AtNRAMP6 might contribute to the uptake of $\mathrm{Cd}$ by the plant. To test this hypothesis, the concentration of $\mathrm{Cd}$ was measured in leaves of WT and nramp6-1 plants grown as described for Figure 5C using AAS. Figure 5D shows that the $\mathrm{Cd}$ concentration did not significantly decrease in nramp6-1 compared to WT plants, neither in isolated petioles and limbs of rosette leaves nor in caulinar leaves. Similar results were obtained in 2 week-old seedlings (Table 1). Therefore, rather than being involved in $\mathrm{Cd}$ entry into the cell, AtNRAMP6 may modify $\mathrm{Cd}$ distribution between subcellular compartments so as to promote $\mathrm{Cd}$-induced damage.

\section{AtNRAMP6 overexpressing lines are hypersensitive to cadmium toxicity}


Wild-type Arabidopsis plants were transformed with the 35S-AtNRAMP6 construct previously used to complement the nramp6-1 phenotype. 10 independent transformants were selected on kanamycin-containing medium and the level of AtNRAMP6 expression was measured by semiquantitative RT-PCR (Figure 6A). The macroscopic phenotype of these overexpressor lines was indistinguishable from the parental line (data not shown). We investigated the capacity of germination in the presence of $\mathrm{Cd}$ of lines \#2, \#3 and \#6, which harbored the highest level of AtNRAMP6 overexpression relative to WT. Compared to WT plants, growth of 35S-AtNRAMP6 plants was more strongly inhibited by $2 \mu \mathrm{M} \mathrm{CdSO}_{4}$ in the medium, as shown for line $\# 2$ (Figure 6B). Quantification of this phenotype was estimated by measuring fresh weight (FW) production in lines \#2, 3 and 6 (Figure 6C). Compared to WT, FW dropped to about of $50 \%$ at $2 \mu \mathrm{M} \mathrm{Cd}$ and $70 \%$ at $10 \mu \mathrm{M} \mathrm{Cd}$. Consistent with this observation, nramp6-1 plants grew better than wild-type plants during the treatment (Figure 6C). Similar to the situation with the nramp6-1 mutant however, the concentration of $\mathrm{Cd}$ measured in the overexpressing lines was not different from that in wild-type plants (Table 1).

\section{Membrane localization of AtNRAMP6 protein}

One hypothesis that could explain these data is that AtNRAMP6 is a Cd transporter responsible for releasing the metal into or from an intracellular organelle. To identify the subcellular location of AtNRAMP6, we have generated transgenic plants producing C-terminal fusions of AtNRAMP6 with either the green fluorescent protein (GFP) or the hemagglutinin (HA) epitope under the control of the CaMV $35 S$ promoter. Although expression of the transgene was strongly detected at the level of transcript accumulation, we failed to detect the fusion proteins either by Western blot or by imaging of the GFP fluorescence (data not shown). We also failed to detect HA or GFP when fused to AtNRAMP6 truncated at the in frame stop codon present in the intron 6 (data not shown). When the 35S-AtNRAMP6::GFP construct was introduced in the nramp6-1 mutant, the fusion protein did accumulate in the plant, as indicated by Western blot, however the fluorescence signal of the GFP was very weak and mostly cytoplasmic (data not shown).

In the absence of functional tools in planta, we addressed the question of the membrane localization of AtNRAMP6 in S. cerevisiae. To identify the target membrane of AtNRAMP6, the protein was epitope-tagged with two repeats of HA and expressed in a wild-type yeast strain under the control of the strong PMA1 promoter. The increase of Cd sensitivity mediated by this construct, though slightly weaker, was in the same range as that observed with the non-tagged AtNRAMP6 protein (Figure 3B, C), indicating that the AtNRAMP6::HA fusion used is functional. Immunoblot analysis of total protein extracted from yeast hybridized with a monoclonal anti-HA antibody enabled the detection of two polypeptides: a major polypeptide at $60 \mathrm{kDa}$ corresponding to the calculated size of AtNRAMP6 fused to 2HA, and a less abundant polypeptide around $30 \mathrm{kDa}$ which is likely to result from a proteolytic cleavage of the full size polypeptide (Figure 7A). Despite AtNRAMP6 mediating Cd hypersensitivity, yeast cells contained the same amount of Cd whether it was transformed with the empty vector, AtNRAMP6 or AtNRAMP6::HA constructs (Figure 7B). This result suggested that in yeast too, AtNRAMP6 may be targeted to an intracellular membrane.

We next fractionated yeast total proteins by differential centrifugation to obtain total membrane proteins (M: microsomal fraction) and a plasmalemma-enriched fraction (PM). Proteins were separated on a SDS-PAGE acrylamide gel, blotted and probed with the anti-HA antibody. The HA signal observed in total protein extracts was amplified in the microsomal 
extract but was totally undetectable in the PM fraction (Figure 7C). Hybridization of the Western blot with antibodies recognizing proteins specific for the plasma membrane (Pma1p), the mitochondria (Cox2p) and the vacuolar membrane (V-ATPase) confirmed that the PM fraction is relatively pure. Therefore AtNRAMP6::HA is not addressed to the plasma membrane of yeast.

We next addressed the intracellular distribution of AtNRAMP6 by immunofluorescence microscopy (Figure 7D). While no fluorescence was observed in cells expressing the untagged allele (data not shown), AtNRAMP6::HA fluorescence was seen as a punctuate signal in the cytoplasm, thereby eliminating the vacuole as a target compartment for AtNRAMP6. In addition, staining with DAPI, a dye that reveals nuclear as well as mitochondrial DNA, indicated that AtNRAMP6 does not co-localize with mitochondria. These observations confirm that AtNRAMP6 is located in an endomembrane compartment different from vacuole or mitochondria.

\section{DISCUSSION}

Among the 6 NRAMP-encoding genes of Arabidopsis, metal transport activity has been reported for AtNRAMP1, 3 and 4. In this study, we describe the molecular and physiological characterization of AtNRAMP6 and show that it alters cellular cadmium sensitivity probably by perturbing intracellular distribution of this metal.

During the process of cloning AtNRAMP6 cDNA, we found that AtNRAMP6 transcripts are often stabilized as partially spliced isoforms, the most common of these retaining the entire intron 6 , resulting in shortening of the open reading frame by about half the length of that encoding the predicted AtNRAMP6 protein. Although alternative splicing is a well-known way to increase protein diversity, a cDNA corresponding to the misspliced isoform turned out to be non functional in our yeast assay. An AtNRAMP6 cDNA reconstructed according to the prediction of splicing however, was functional in yeast. The biological significance of this missplicing is unclear. We found that both AtNRAMP6 species coexist in all the tissues tested and were unable to find conditions where the fully spliced isoform exclusively is produced, thus arguing against the idea that AtNRAMP6 expression is regulated at the level of mRNA splicing. Furthermore, plants overexpressing the truncated form of AtNRAMP6 did not harbor any growth defect whatsoever (data not shown).

Our data suggest that AtNRAMP6 is a cadmium transporter since when expressed in Saccharomyces cerevisiae or when overexpressed in Arabidopsis, AtNRAMP6 confers increased sensitivity to $\mathrm{Cd}$. Consistently, growth of the nramp6-1 loss-of-function mutant is unaffected by otherwise toxic concentrations of $\mathrm{Cd}$ and this tolerance is reverted by complementation with a 35S-AtNRAMP6 construct. The finding that AtNRAMP6 may be capable of transporting Cd is reminiscent of several other NRAMP proteins. First in plants, AtNRAMP1, 3 and 4 were previously shown to mediate $\mathrm{Cd}$ toxicity and increased cellular $\mathrm{Cd}$ content when expressed in yeast, whereas Arabidopsis lines overexpressing AtNRAMP3 were found hypersensitive to $\mathrm{Cd}$ [26]. Similar results were obtained for the Thlaspi caerulescens member TcNRAMP3 when expressed in yeast or in tobacco [27]. MntH, the prokaryotic NRAMP ortholog, is a Fe/Mn transporter that confers Cd hypersensitivity when overexpressed in bacteria [40]. Very close to $\mathrm{MntH}$, Chlamydomonas reinhardtii DMT1 restores growth of the yeast $\Delta s m f 1$ mutant and mediates hypersensitivity to $\mathrm{Cd}$ [25]. Nramp2 in mammals was also shown in vitro to work as a 
cadmium transporter [17] but although it represents a candidate for Cd uptake at the brush border of the duodenum [41], intestinal cadmium absorption was recently shown to be unaffected in the DMT1-dysfunctional $m k / m k$ mice [42].

Using immunological approaches, we have established that AtNRAMP6 is not located at the cell surface, but is located in a punctuate-shaped endomembrane compartment, distinct from mitochondria and from the vacuole. This intracellular localization is consistent with AtNRAMP6 conferring $\mathrm{Cd}$ sensitivity without affecting $\mathrm{Cd}$ content in yeast cells and plant tissues, as one would expect if localized on the plasma membrane. Consequently, the $\mathrm{Cd}$ sensitivity induced by AtNRAMP6 is not due to net influx of $\mathrm{Cd}$ but rather results from the redistribution of internal $\mathrm{Cd}$ pools. AtNRAMP6 could induce Cd toxicity in two ways: either by remobilizing the metal from a detoxifying compartment into the cytosol, thus increasing its availability/toxicity, or by promoting its allocation into an organelle sensitive to Cd-induced damages. However the fact that NRAMP family members use the proton motive force to transport metals [17] supports the view that AtNRAMP6 is targeted to an acidic compartment in order to catalyze the flux of Cd toward the cytosol. In spite of the fact that the vacuole in yeast is responsible for $\mathrm{Cd}$ detoxification through the transport of Cd-GS 2 complexes [11], we have clearly shown by immunolocalization that AtNRAMP6 is not located in the yeast vacuolar membrane. In addition to the vacuole, ERderived vesicles represent putative sites of $\mathrm{Cd}$ accumulation in plants. Indeed, in onion epidermal cells exposed to $\mathrm{Cd}$ and lead, accumulation of these metals is observed in vesicles derived from the fragmentation of the endoplasmic reticulum [43]. But whether the ER is a detoxifying compartment for $\mathrm{Cd}$ or a location where it exerts its toxicity is not clear. In mammalian cells, the well known phenomenon of Cd-triggered apoptosis, which is in part due to dysfunction of mitochondria, was recently also attributed to ER stress in some cell types [44]. This suggests that ER could be a target of Cd toxicity. Immunolabeling of AtNRAMP6 in yeast is compatible with an ER localization. However, the $\mathrm{pH}$ of the ER, which was reported to be neutral [45], is not optimal for NRAMP activity that requires a proton gradient across the membrane to function. On the contrary, the lumen of the peroxisomes is alkaline [46] and could provide the proton motive force for AtNRAMP6, which would thus transport metals from the cytosol towards the peroxisome. Finally, the vesicular localization of AtNRAMP6 is reminiscent of that of its yeast homologue, Smf2p, which resides in intracellular vesicles and seems to play a central role in the delivery of Mn to various cellular sites including mitochondria [47]. Whether AtNRAMP6 and Smf2p have similar cellular functions should be investigated in future work.

Although Cd seems to be a substrate for AtNRAMP6, which enabled us to reveal its role as a metal transporter, Cd transport is likely not the primary function of AtNRAMP6 in the plant. What then could be the physiological substrate of AtNRAMP6? Elemental analysis by AAS of nramp6-1 plant tissues did not reveal any change in metal content, which might provide a clue as to AtNRAMP6's physiological function (data not shown). In addition, we were unable to see growth restoration of yeast Fe, $\mathrm{Zn}$ or Mn uptake defective mutants by AtNRAMP6. However, we cannot exclude the possibility that AtNRAMP6 accepts physiological metals such as Fe or Mn as a substrate because, based on immunofluorescence microscopy and immunoblot analyses, AtNRAMP6 is exclusively targeted to intracellular membranes of yeast. In plants, we failed to detect any alteration of growth of the nramp6-1 mutant in response to deficiency or excess of $\mathrm{Fe}$, $\mathrm{Mn}$ or $\mathrm{Cu}$ (Supplementary Figure S1), suggesting that AtNRAMP6 is not essential to maintain the homeostasis of these metals.

One explanation for the lack of metal-related phenotype of the nramp6-1 mutant could be the existence of a functional redundancy between AtNRAMP members, as previously shown for AtNRAMP3 and AtNRAMP4 [29]. Given that AtNRAMP1 and AtNRAMP6 are highly 
homologous proteins, we generated an Arabidopsis line knocked out in both AtNRAMP1 and AtNRAMP6 genes; this nramp1 nramp6 double mutant also failed to develop any metal-related phenotype however (data not shown). Though phylogenically very close, AtNRAMP1 and AtNRAMP6 do not share the same territories of expression, the former being mostly expressed in roots [22] and the latter in seeds and shoots (this work). Combination of the nramp6 mutation with a mutation in another AtNRAMP gene expressed in overlapping territories may provide information on AtNRAMP6 function in the plant. We found AtNRAMP6 promoter to be mostly active in the cotyledons at the embryonic stage, which is consistent with the increased tolerance to Cd of nramp6-1 embryos at germination. However we did not measure any variation of the total amount of metals (Fe, $\mathrm{Mn}, \mathrm{Zn}, \mathrm{Cu}, \mathrm{Cd}$ ) in nramp6-1 seeds (data not shown). Both the expression pattern in the cotyledons and the lack of metal content variation in seeds are reminiscent of AtNRAMP3 and AtNRAMP4 [29]. In addition overexpression of AtNRAMP3, like AtNRAMP6, generates Arabidopsis plants hypersensitive to Cd [26] (this study). AtNRAMP3 and AtNRAMP4 are tonoplastic proteins, an intracellular localization that is clearly different from the vesicular location observed for AtNRAMP6. Like AtNRAMP6, the overexpression of AtNRAMP3 increases the plant sensitivity to Cd [45], which suggests that AtNRAMP3, AtNRAMP4 and AtNRAMP6 may contribute, through parallel transport pathways, to the availability of $\mathrm{Cd}$ in cellular compartments sensitive to $\mathrm{Cd}$ toxicity. In this scenario, analysis of the double nramp3 nramp6 or nramp4 nramp6 mutants may reveal a role for AtNRAMP6 in metal mobilization/sequestration during germination.

In conclusion, this report describes a new member of the NRAMP family of metal transporters. The AtNRAMP6 gene encodes a protein shown in this study to be functional and potentially involved in $\mathrm{Cd}$ tolerance. The protein, shown in yeast to be targeted to intracellular vesicles, may mediate the transport of $\mathrm{Cd}$ from internal pools. Taken together, our results and the already known mechanisms of $\mathrm{Cd}$ toxicity and detoxification open new perspectives to integrate the role of NRAMP proteins in the homeostasis of metals and the detoxification of non-essential pollutants.

\section{ACKNOWLEDGEMENTS}

We are indebted to Dr Sébastien Thomine (ISV Gif-sur-Yvette, France) for providing the initial intron-containing AtNRAMP 6 clone in the pGEM ${ }^{\circledR}-\mathrm{T}$ Easy vector. We thank David Eide for the generous gift of yeast anti-Cox $2 p$ and anti-V-ATPase antisera.

\section{FUNDING}

This work was supported by the Centre National de la Recherche Scientifique (CNRS), the Institut National de la Recherche Agronomique (INRA) and the ANR program 07-3-18-8-87 DISTRIMET. R.C. was supported by the French Ministry of Agriculture and Fisheries. 


\section{REFERENCES}

1 Lane, T. W., Saito, M. A., George, G. N., Pickering, I. J., Prince, R. C. and Morel, F. M. (2005) Biochemistry: a cadmium enzyme from a marine diatom. Nature. 435, 42

2 Bertin, G. and Averbeck, D. (2006) Cadmium: cellular effects, modifications of biomolecules, modulation of DNA repair and genotoxic consequences (a review). Biochimie. 88, 1549-1559

3 Clemens, S. (2006) Toxic metal accumulation, responses to exposure and mechanisms of tolerance in plants. Biochimie. 88, 1707-1719

4 Perfus-Barbeoch, L., Leonhardt, N., Vavasseur, A. and Forestier, C. (2002) Heavy metal toxicity: cadmium permeates through calcium channels and disturbs the plant water status. Plant J. 32, 539-548

5 Eide, D., Broderius, M., Fett, J. and Guerinot, M. L. (1996) A novel iron-regulated metal transporter from plants identified by functional expression in yeast. Proc. Natl Acad. Sci. U. S. A. 93, 5624-5628

6 Rogers, E. E., Eide, D. J. and Guerinot, M. L. (2000) Altered selectivity in an Arabidopsis metal transporter. Proc. Natl Acad. Sci. U. S. A. 97, 12356-12360

7 Vert, G., Grotz, N., Dedaldechamp, F., Gaymard, F., Guerinot, M. L., Briat, J. F. and Curie, C. (2002) IRT1, an Arabidopsis Transporter Essential for Iron Uptake from the Soil and for Plant Growth. Plant Cell. 14, 1223-1233.

8 Liu, Z., Li, H., Soleimani, M., Girijashanker, K., Reed, J. M., He, L., Dalton, T. P. and Nebert, D. W. (2008) Cd2+ versus Zn2+ uptake by the ZIP8 HCO3--dependent symporter: kinetics, electrogenicity and trafficking. Biochem Biophys Res Commun. 365, 814-820

9 Cobbett, C. S. (2000) Phytochelatins and their roles in heavy metal detoxification [In Process Citation]. Plant Physiol. 123, 825-832

10 Ha, S. B., Smith, A. P., Howden, R., Dietrich, W. M., Bugg, S., O'Connell, M. J., Goldsbrough, P. B. and Cobbett, C. S. (1999) Phytochelatin synthase genes from Arabidopsis and the yeast Schizosaccharomyces pombe. Plant Cell. 11, 1153-1164

11 Li, Z. S., Lu, Y. P., Zhen, R. G., Szczypka, M., Thiele, D. J. and Rea, P. A. (1997) A new pathway for vacuolar cadmium sequestration in Saccharomyces cerevisiae: YCF1-catalyzed transport of bis(glutathionato)cadmium. Proc Natl Acad Sci U S A. 94, 42-47

12 Ortiz, D. F., Ruscitti, T., McCue, K. F. and Ow, D. W. (1995) Transport of metal-binding peptides by HMT1, a fission yeast ABC-type vacuolar membrane protein. J Biol Chem. 270, 4721-4728

13 Kim, D. Y., Bovet, L., Maeshima, M., Martinoia, E. and Lee, Y. (2007) The ABC transporter AtPDR8 is a cadmium extrusion pump conferring heavy metal resistance. Plant J. 50, 207-218

14 Williams, L. E. and Mills, R. F. (2005) P(1B)-ATPases--an ancient family of transition metal pumps with diverse functions in plants. Trends Plant Sci. 10, 491-502

15 Hanikenne, M., Talke, I. N., Haydon, M. J., Lanz, C., Nolte, A., Motte, P., Kroymann, J., Weigel, D. and Kramer, U. (2008) Evolution of metal hyperaccumulation required cisregulatory changes and triplication of HMA4. Nature. 453, 391-395

16 Verret, F., Gravot, A., Auroy, P., Leonhardt, N., David, P., Nussaume, L., Vavasseur, A. and Richaud, P. (2004) Overexpression of AtHMA4 enhances root-to-shoot translocation of zinc and cadmium and plant metal tolerance. FEBS Lett. 576, 306-312 
17 Gunshin, H., Mackenzie, B., Berger, U. V., Gunshin, Y., Romero, M. F., Boron, W. F., Nussberger, S., Gollan, J. L. and Hediger, M. A. (1997) Cloning and characterization of a mammalian proton-coupled metal-ion transporter. Nature. 388, 482-488

18 Vidal, S. M., Malo, D., Vogan, K., Skamene, E. and Gros, P. (1993) Natural resistance to infection with intracellular parasites: isolation of a candidate for Bcg. Cell. 73, 469-485

19 Fleming, M. D., Trenor, C. C. r., Su, M. A., Foernzler, D., Beier, D. R., Dietrich, W.F. and Andrews, N. C. (1997) Microcytic anaemia mice have a mutation in Nramp2, a candidate iron transporter gene. Nat. Genet. 16, 383-386

20 Tabuchi, M., Yoshimori, T., Yamaguchi, K., Yoshida, T. and Kishi, F. (2000) Human NRAMP2/DMT1, which mediates iron transport across endosomal membranes, is localized to late endosomes and lysosomes in HEp-2 cells. J Biol Chem. 275, 22220-22228

21 Belouchi, A., Kwan, T. and Gros, P. (1997) Cloning and characterization of the OsNramp family from Oryza sativa, a new family of membrane proteins possibly implicated in the transport of metal ions. Plant Mol. Biol. 33, 1085-1092

22 Curie, C., Alonso, J. M., Le Jean, M., Ecker, J. R. and Briat, J. F. (2000) Involvement of NRAMP1 from Arabidopsis thaliana in iron transport. Biochem. J. 347, 749-755

23 Kaiser, B. N., Moreau, S., Castelli, J., Thomson, R., Lambert, A., Bogliolo, S., Puppo, A. and Day, D. A. (2003) The soybean NRAMP homologue, GmDMT1, is a symbiotic divalent metal transporter capable of ferrous iron transport. Plant J. 35, 295-304

24 Mizuno, T., Usui, K., Horie, K., Nosaka, S., Mizuno, N. and Obata, H. (2005) Cloning of three ZIP/Nramp transporter genes from a Ni hyperaccumulator plant Thlaspi japonicum and their Ni2+-transport abilities. Plant Physiol Biochem. 43, 793-801

25 Rosakis, A. and Koster, W. (2005) Divalent metal transport in the green microalga Chlamydomonas reinhardtii is mediated by a protein similar to prokaryotic Nramp homologues. Biometals. 18, 107-120

26 Thomine, S., Wang, R., Ward, J. M., Crawford, N. M. and Schroeder, J. I. (2000) Cadmium and iron transport by members of a plant metal transporter family in Arabidopsis with homology to Nramp genes. Proc. Natl Acad. Sci. U. S. A. 97, 4991-4996

27 Wei, W., Chai, T., Zhang, Y., Han, L., Xu, J. and Guan, Z. (2008) The Thlaspi caerulescens NRAMP Homologue TcNRAMP3 is Capable of Divalent Cation Transport. Mol Biotechnol

28 lanquar, V., Lelièvre, F., Barbier-brygoo, H. and Thomine, S. (2004) Regulation and function of AtNRAMP4 metal transporter protein. Soil Sci. Plant Nutr. 50, 1141-1150

29 Lanquar, V., Lelievre, F., Bolte, S., Hames, C., Alcon, C., Neumann, D., Vansuyt, G., Curie, C., Schroder, A., Kramer, U., Barbier-Brygoo, H. and Thomine, S. (2005) Mobilization of vacuolar iron by AtNRAMP3 and AtNRAMP4 is essential for seed germination on low iron. Embo J. 24, 4041-4051

30 Thomine, S., Lelievre, F, Debarbieux, E., Schroeder, J. I. and Barbier-Brygoo, H. (2003) AtNRAMP3, a multispecific vacuolar metal transporter involved in plant responses to iron deficiency. Plant J. 34, 685-695

31 Friedrichsen, D. M., Joazeiro, C. A., Li, J., Hunter, T. and Chory, J. (2000) Brassinosteroidinsensitive- 1 is a ubiquitously expressed leucine-rich repeat receptor serine/threonine kinase. Plant Physiol. 123, 1247-1256

32 Rentsch, D., Laloi, M., Rouhara, I., Schmelzer, E., Delrot, S. and Frommer, W. B. (1995) NTR1 encodes a high affinity oligopeptide transporter in Arabidopsis. FEBS Lett. 370, 264268

33 Eyal, Y., Curie, C. and McCormick, S. (1995) Pollen specificity elements reside in 30 bp of the proximal promoters of two pollen-expressed genes. Plant Cell. 7, 373-384 
34 Bevan, M. (1984) Binary Agrobacterium vectors for plant transformation. Nucl. Acids Res. 12, $8711-8721$

35 Murashige, T. and Skoog, F. (1962) A revised medium for rapid growth and bioassays with tobacco tissue cultures. Physiol. Plant. 15, 473-497

36 Clough, S. J. and Bent, A. F. (1998) Floral dip: a simplified method for Agrobacteriummediated transformation of Arabidopsis thaliana. Plant J. 16, 735-743

37 Delom, F., Szponarski, W., Sommerer, N., Boyer, J. C., Bruneau, J. M., Rossignol, M. and Gibrat, R. (2006) The plasma membrane proteome of Saccharomyces cerevisiae and its response to the antifungal calcofluor. Proteomics. 6, 3029-3039

38 Bradford, M. M. (1976) A rapid and sensitive method for the quantitation of microgram quantities of protein utilizing the principle of protein-dye binding. Anal. Biochem. 72, 248254

39 Pintard, L., Kressler, D. and Lapeyre, B. (2000) Spblp is a yeast nucleolar protein associated with Nop1p and Nop58p that is able to bind S-adenosyl-L-methionine in vitro. Mol Cell Biol. 20, 1370-1381

40 Makui, H., Roig, E., Cole, S. T., Helmann, J. D., Gros, P. and Cellier, M. F. (2000) Identification of the Escherichia coli K-12 Nramp orthologue (MntH) as a selective divalent metal ion transporter. Mol Microbiol. 35, 1065-1078

41 Okubo, M., Yamada, K., Hosoyamada, M., Shibasaki, T. and Endou, H. (2003) Cadmium transport by human Nramp 2 expressed in Xenopus laevis oocytes. Toxicol Appl Pharmacol. 187, 162-167

42 Suzuki, T., Momoi, K., Hosoyamada, M., Kimura, M. and Shibasaki, T. (2008) Normal cadmium uptake in microcytic anemia mk/mk mice suggests that DMT1 is not the only cadmium transporter in vivo. Toxicol Appl Pharmacol. 227, 462-467

43 Wierzbicka, M. H., Przedpelska, E., Ruzik, R., Ouerdane, L., Polec-Pawlak, K., Jarosz, M., Szpunar, J. and Szakiel, A. (2007) Comparison of the toxicity and distribution of cadmium and lead in plant cells. Protoplasma. 231, 99-111

44 Yokouchi, M., Hiramatsu, N., Hayakawa, K., Kasai, A., Takano, Y., Yao, J. and Kitamura, M. (2007) Atypical, bidirectional regulation of cadmium-induced apoptosis via distinct signaling of unfolded protein response. Cell Death Differ. 14, 1467-1474

45 Paroutis, P., Touret, N. and Grinstein, S. (2004) The pH of the secretory pathway: measurement, determinants, and regulation. Physiology (Bethesda). 19, 207-215

46 van Roermund, C. W., de Jong, M., L, I. J., van Marle, J., Dansen, T. B., Wanders, R. J. and Waterham, H. R. (2004) The peroxisomal lumen in Saccharomyces cerevisiae is alkaline. J Cell Sci. 117, 4231-4237

47 Luk, E. E. and Culotta, V. C. (2001) Manganese Superoxide Dismutase in Saccharomyces cerevisiae Acquires Its Metal Co-factor through a Pathway Involving the Nramp Metal Transporter, Smf2p. J Biol Chem. 276, 47556-47562. 


\section{FIGURE LEGENDS}

\section{Table 1 AtNRAMP6 does not affect total cadmium concentration in plants}

AAS measurement of $\mathrm{Cd}$ in plants grown in vitro for 10 days in the presence of $5 \mu \mathrm{M}$ CdSO4. S.E. stands for standard error.

\section{Figure 1 AtNRAMP6 protein sequence and topology}

(A) Alignment of the Arabidopsis NRAMP protein family generated using ClustalW (http://align.genome.jp/) and Boxshade (http://www.ch.embnet.org/software/BOX_doc.html). The Consensus transport motif (CTM) is indicated. (B) AtNRAMP6 is an integral membrane protein predicted to have 12 transmembrane domains ${ }^{\mathrm{TM}}$. The amino acid residues that are circled in the cytoplasmic loop between TM8 and TM9 constitute the consensus transport motif. The position of the putative N-glycosylation site is indicated as a circle in the third extracellular loop. The topology was predicted using the TMHMM v. 2.0 program (http://www.cbs.dtu.dk/services/TMHMM-2.0) coupled to the TMD pred ${ }^{\mathrm{R}}$ software.

\section{Figure 2 Two AtNRAMP6 transcript isoforms coexist in the plant}

(A) Nucleotide sequence alignment between the intron-retaining AtNRAMP6 clone (NRAMP6-I6: RAFL05-14-K06 clone, Riken), the fully spliced deduced AtNRAMP6 cDNA (NRAMP6) and the AtNRAMP 1 cDNA, in the region encompassing exon 5 to exon 7 . Nucleotides are numbered from the ATG initiation codon. The in-frame stop codon in the intron 6 is boxed. (B) Structure of the misspliced AtNRAMP6 transcript and position of the primers used in the RT-PCR reaction presented in panel $C$. (C) Differential expression of the two isoforms of AtNRAMP6 mRNA in planta; PCR control on plasmid DNA containing either the misspliced cDNA showing a DNA fragment at $284 \mathrm{pb}$ (a) or the spliced cDNA showing a DNA fragment at $216 \mathrm{pb}$ (b); The size markers lane (M) shows a DNA fragment at $0.2 \mathrm{kbp}$ and $0.3 \mathrm{kbp}$. Semi-quantitative RT-PCR performed on total RNA extracted from various plant tissues: roots (c), shoots (d), young leaves (e), floral buds (f), open flowers (g), peduncles of siliques (h), siliques (i).

\section{Figure 3 Expression of AtNRAMP6 in yeast results in increased cadmium sensitivity}

(A) (B) Assay of cadmium tolerance. Wild-type W303 cells transformed with the pDR195 empty vector, or the pDR195 vector containing either the misspliced AtNRAMP6 cDNA (NR6-I6), or the reconstructed AtNRAMP6 cDNA untagged (NR6) or tagged with HA (NR6::HA) were grown for 3 days in YNB medium supplemented (B) or not (A) with $25 \mu \mathrm{M} \mathrm{CdSO}_{4}$. $5 \mathrm{X}$ serial dilutions of the cultures, starting at $\mathrm{D}_{600} 1$, were plated. (C) Cadmium induced-growth inhibition test. Clones described in panel $A$ and $B$ were grown for $12 \mathrm{~h}$ in YNB liquid medium containing increasing concentrations of $\mathrm{CdSO}_{4}$ as indicated in the Figure and $\mathrm{D}_{600}$ was determined. For each construct, the values represent the mean of values obtained with 3 independent clones. The graph shown is representative of two independent experiments.

\section{Figure 4 Expression analysis of $A t N R A M P 6$}


(A-C) Real time RT-PCR measurement of AtNRAMP6 transcript accumulation, calculated relative to the actin transcript level, on total RNA extracted from either seedlings germinated for the amount of time indicated on the figure (A), or from 14 day-old plantlets grown in vitro (B), or mature aerial organs harvested from soil-grown plants (C). (D) Tissue-specific activity of AtNRAMP6 promoter. Histochemical staining of ß-Glucuronidase (GUS) activity in Arabidopsis transgenic plants expressing the uidA gene under the control of $1.45 \mathrm{~kb}$ of AtNRAMP6 promoter sequence. (a) Embryo dissected from imbibed seed; (b) Plantlet 3 days post germination; (c) flowers; (d) Mature rosette leaf; (e) silique peduncle; (f) open silique showing staining of the funiculi. L: leaves, SL: senescent leaves, FB: flower buds, OF: open flowers, SP: silique peduncles, S: siliques.

\section{Figure 5 The nramp6-1 mutant is tolerant to cadmium}

(A) Position of insertion of the two inverted repeated T-DNAs, represented by an arrow that points to the left border, in the intron 9 of AtNRAMP6 genomic sequence. (B) RT-PCR experiment on total RNA extracted from WT and nramp6-1 in vitro-grown plants confirming the absence of AtNRAMP6 mRNA in the mutant. Amplification of actin is shown to control for RNA loading. (C) Typical phenotype of hypertolerance to cadmium of a nramp6-1 plant grown in soil and irrigated with $10 \mu \mathrm{M} \mathrm{CdSO}_{4}$ during 10 days. Compared to the yellow rosette leaves of the wild-type plant, nramp6-1 leaves remain green upon Cd treatment. (D) Cadmium concentration measured by atomic absorption spectrometry (AAS) on tissues harvested from plants cultivated as in (C). Values represent the mean from 5 individually grown adult plants. Error bars represent the standard deviations.

\section{Figure 6 AtNRAMP6 overexpressing plants are hypersensitive to cadmium toxicity}

(A) Accumulation of AtNRAMP6 mRNA in 3 overexpressing lines as measured by semiquantitative RT-PCR on leaf total RNA extracts. Actin mRNA was used to control RNA loading. (B) Phenotype of a representative overexpressing line after 7 days of growth in vitro in the presence of $2 \mu \mathrm{M} \mathrm{CdSO}_{4}$. (C) Growth rate in the presence of cadmium of 3 AtNRAMP6 overexpressing lines compared to wild-type plants (Col-0) and the nramp6-1 mutant. Plants were grown 14 days on plates containing the indicated amount of $\mathrm{CdSO}_{4}$ prior to harvest shoots for fresh weight determination. Each value was obtained from 14 plants and represents the mean of 3 independent measurements. Error bars represent the standard deviations.

\section{Figure 7 AtNRAMP6 is localized in an endomembrane compartment in yeast}

(A) Immunoblot detection of AtNRAMP6::HA in total proteins extracts obtained from yeast transformed with either the pDR195/NRAMP6::HA construct or the empty pDR195 vector and probed with an anti-HA antibody. (B) Cadmium content measured by ICP-MS in wild-type yeast expressing AtNRAMP6 (white bar), or HA-tagged AtNRAMP6 (grey bar), or the empty vector pDR195 (back bar) and grown in the presence of $2 \mu \mathrm{M} \mathrm{CdSO}_{4}$. (C) Immunoblot detection of AtNRAMP6::HA in protein fractions.Total: total proteins extract; M: microsomal fraction; PM: plasma membrane-enriched fraction. The purity of the plasma membrane fraction is controlled by 
hybridization with antibodies directed against the yeast plasma membrane ATPase Pma1p, the yeast mitochondrial protein Cox $2 p$, and the yeast vacuolar membrane V-ATPase. (D) Indirect immunofluorescence detection of AtNRAMP6::HA in fixed yeast cells. a) cells were stained with mouse monoclonal anti-HA antibodies, which were then revealed with an anti-mouse coupled to Alexa 546; b) DAPI staining reveals structures containing DNA, here nuclei and mitochondria; c) overlay. Insert: enlargement of one cell revealing that HA-staining is distinct from the mitochondrial DNA staining. 


\section{Table 1}

Cadmium concentration (mg. $\mathrm{g}^{-1}$ ) measured by AAS in Arabidopsis seedlings

\begin{tabular}{lll}
\hline Genotype & Mean value & S.E. \\
\hline WT & 131.892 & 10.018 \\
nramp6-1 & 116.630 & 7.110 \\
35S-NR6 \# 2 & 107.200 & 20,244 \\
35S-NR6 \# 3 & 118.759 & 15.645 \\
\hline
\end{tabular}


Biochemical Journal Immediate Publication. Published on 22 Jun 2009 as manuscript BJ20090655

A

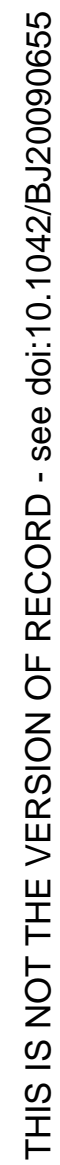

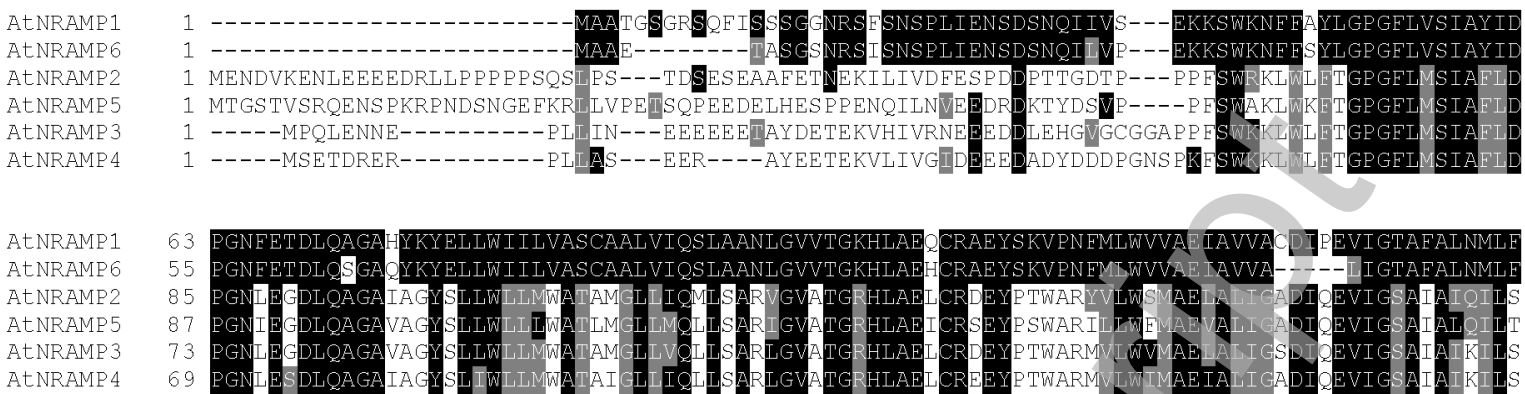

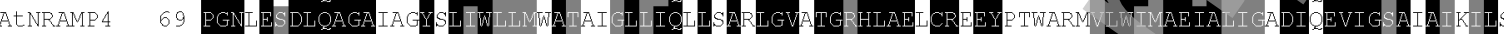
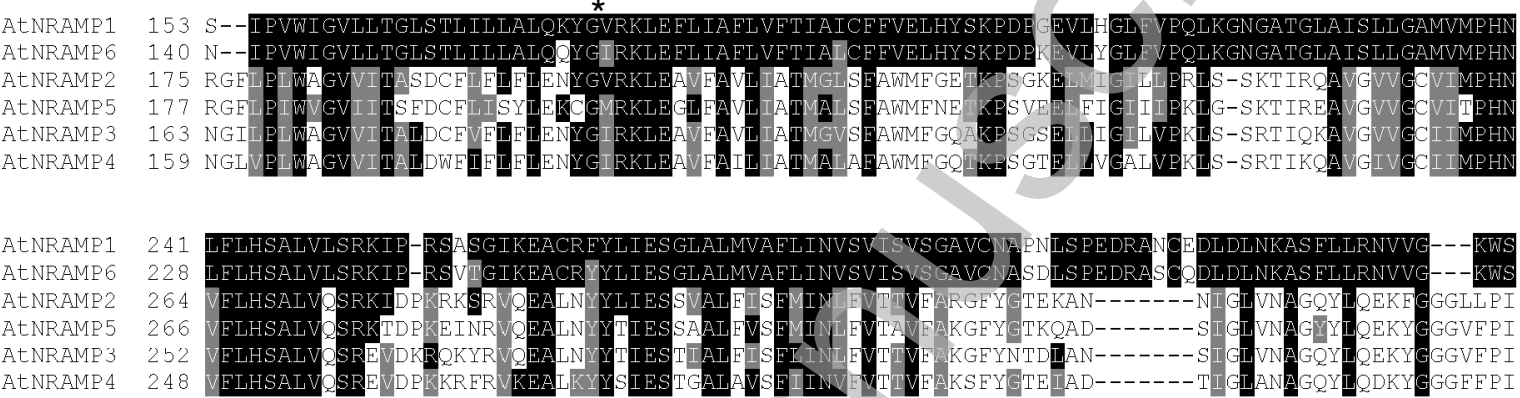

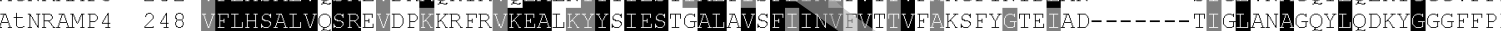
CTM

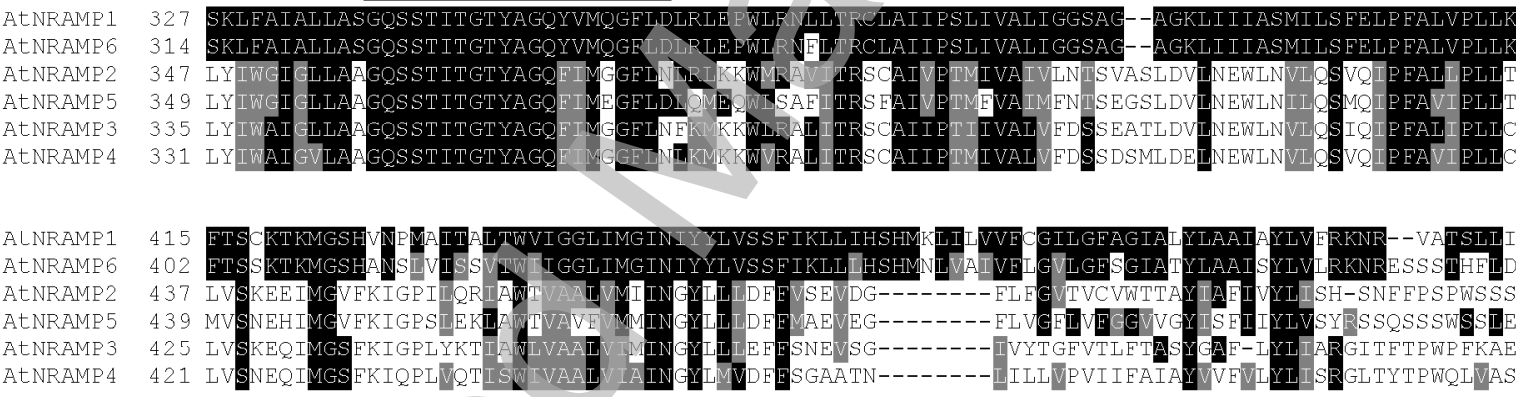

ALNRAMF1 503 SRDSQNVETLPRQDIVNMOLACRYSTS-DVD

ATNRAMF2 518 SIELPKRVISVNS--

ATNRAMT5 $521 \mathrm{MS}$

AtNRAMP 306 S

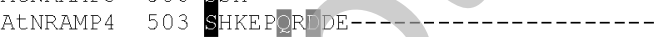

B

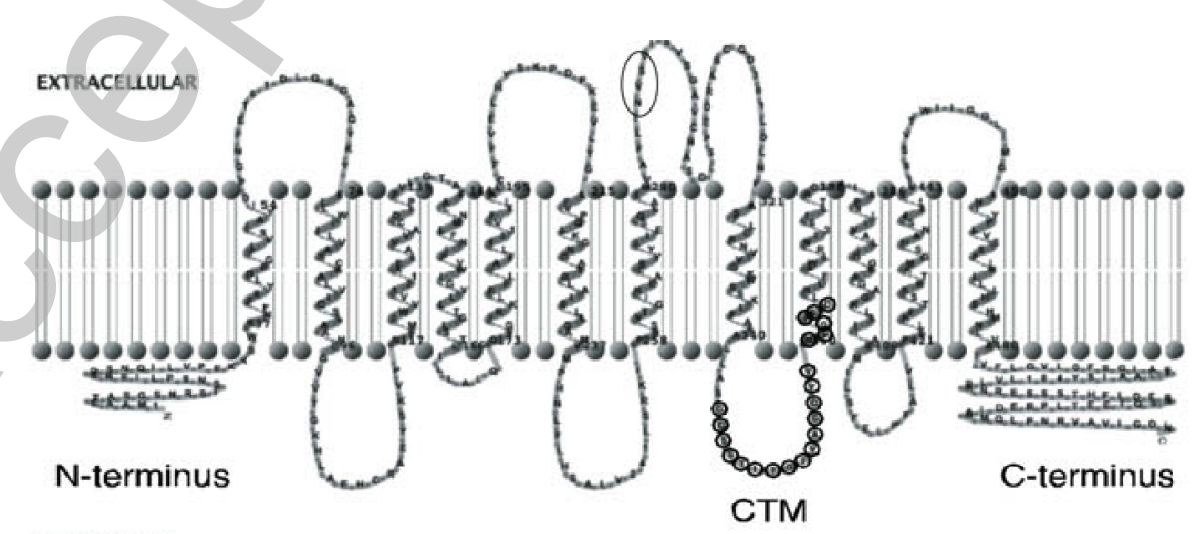

CYTOPLASMIC

Licenced copy. Copying is not permitted, except with prior permission and as allowed by law.

(C) 2009 The Authors Journal compilation (c) 2009 Portland Press Limited 
A

NRAMP6-l6 CTICTCACAGGACT TAGTACATTGAT TCTTCTAGCAC TPCAACAMTATGGGgtacatttg 516 NRAMP6 CTTCTCACAGGACTTAGTACATTGATTCTTCTAGCAC TTCAACAATATGGG--------- 507

NRAMP1 CTTCTGACAGGCTTAAGTACGCTGATTCTTCTCGCACTTCAAAAATACGGG-

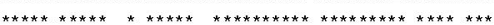

NRAMP6-16 ttaagttttgtttattatggcttttaagtctataaat tggtattttggttctttttatat NRAMPG NRAMP1

NRAMP6-16

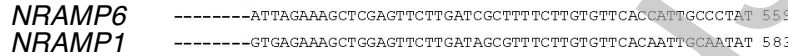

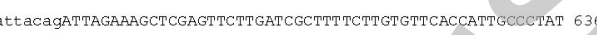

B

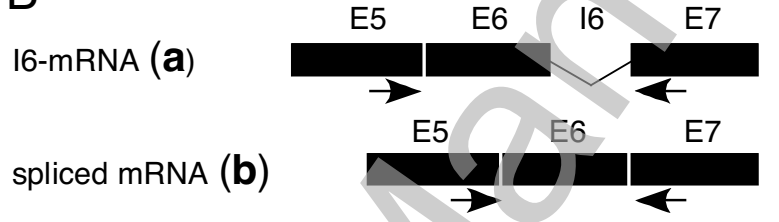

C

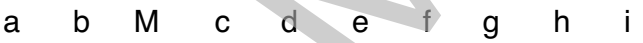

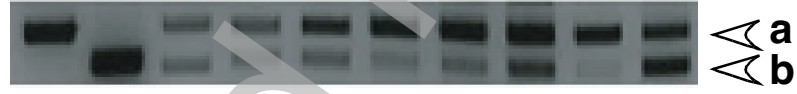

Licenced copy. Copying is not permitted, except with prior permission and as allowed by law. (C) 2009 The Authors Journal compilation (c) 2009 Portland Press Limited 
Biochemical Journal Immediate Publication. Published on 22 Jun 2009 as manuscript BJ20090655

A No Cd

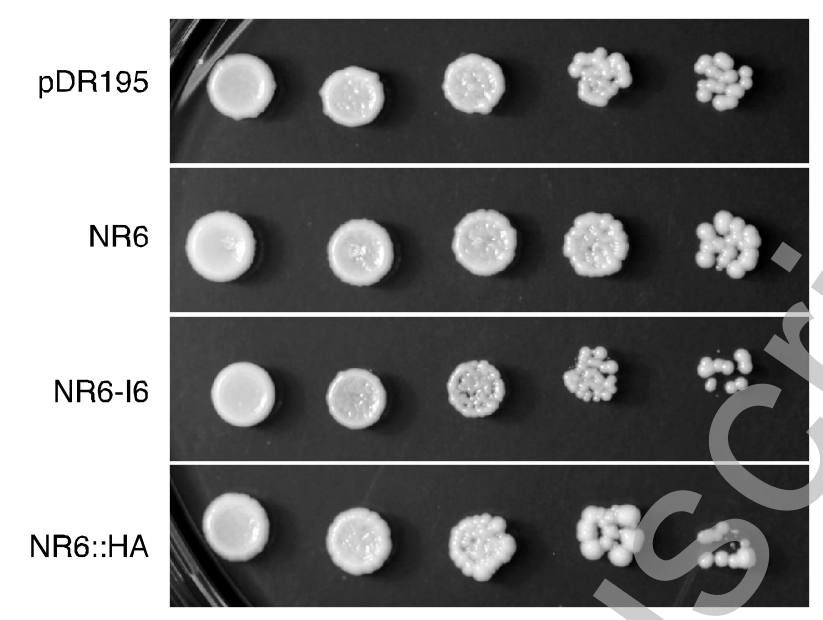

B

$25 \mu \mathrm{M} \mathrm{CdSO}_{4}$

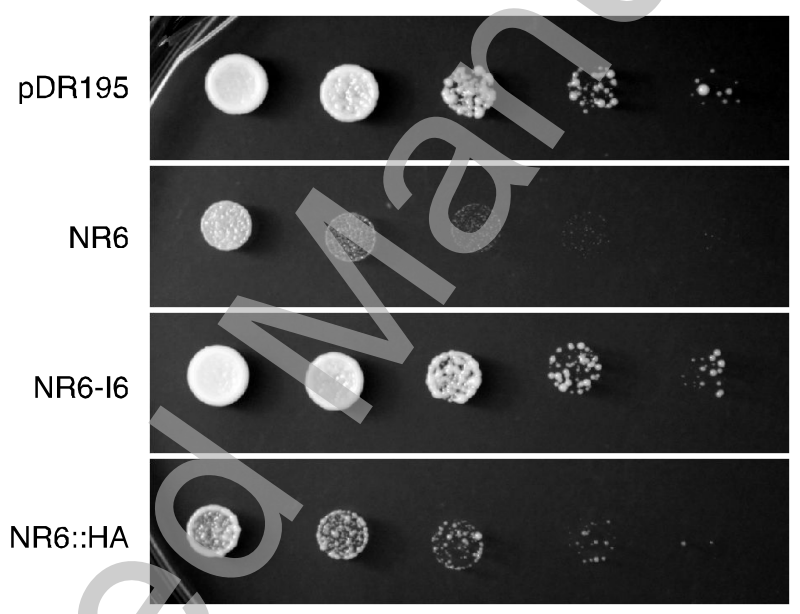

C

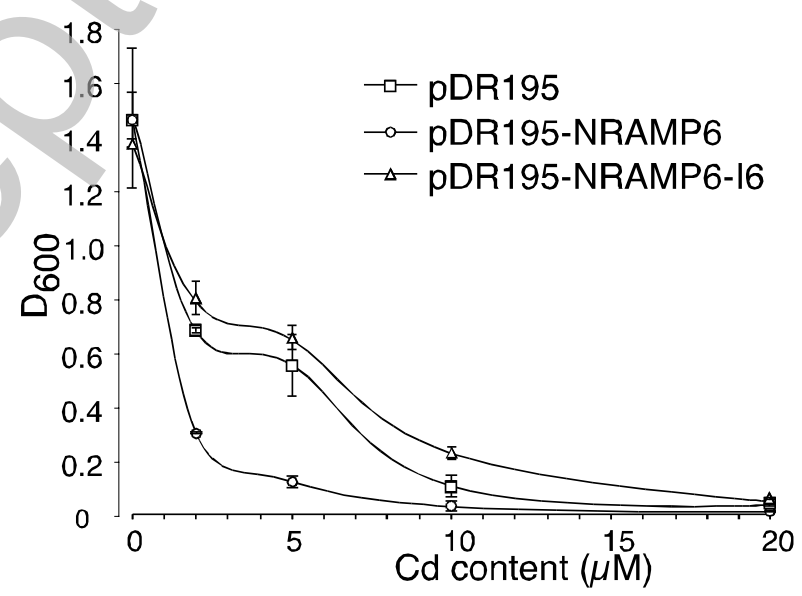



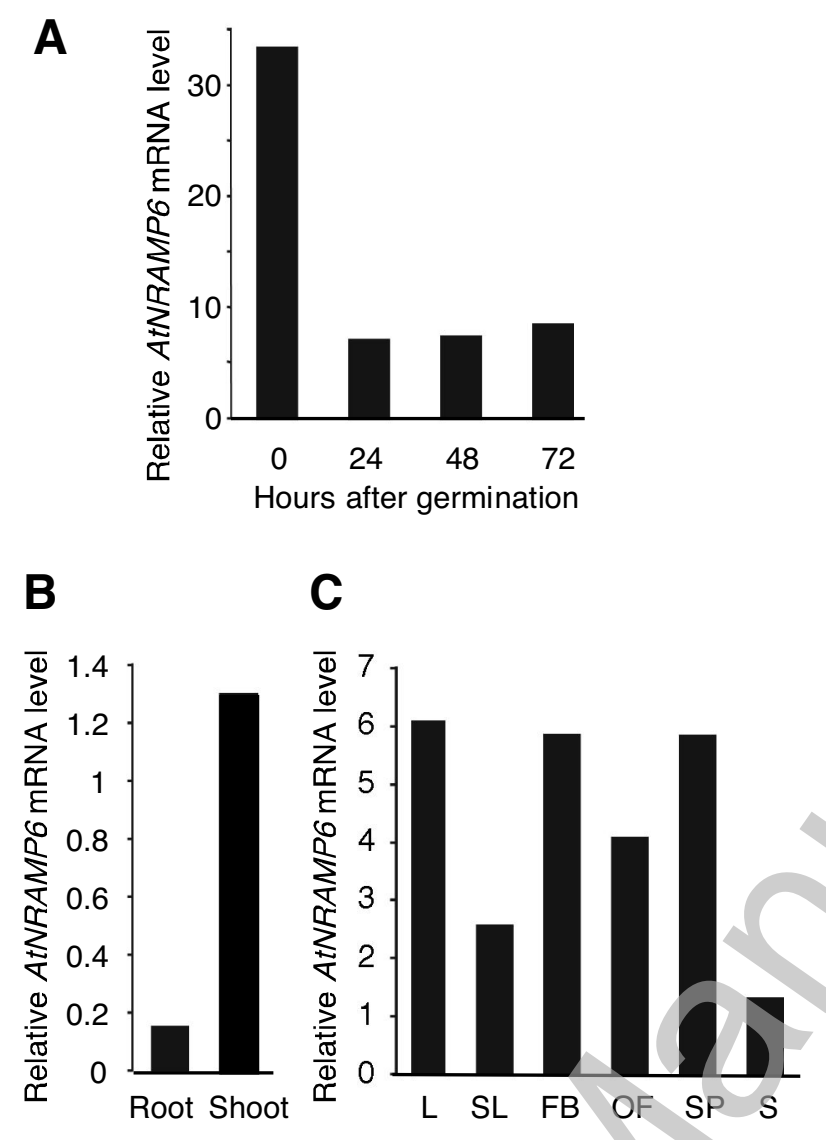

D
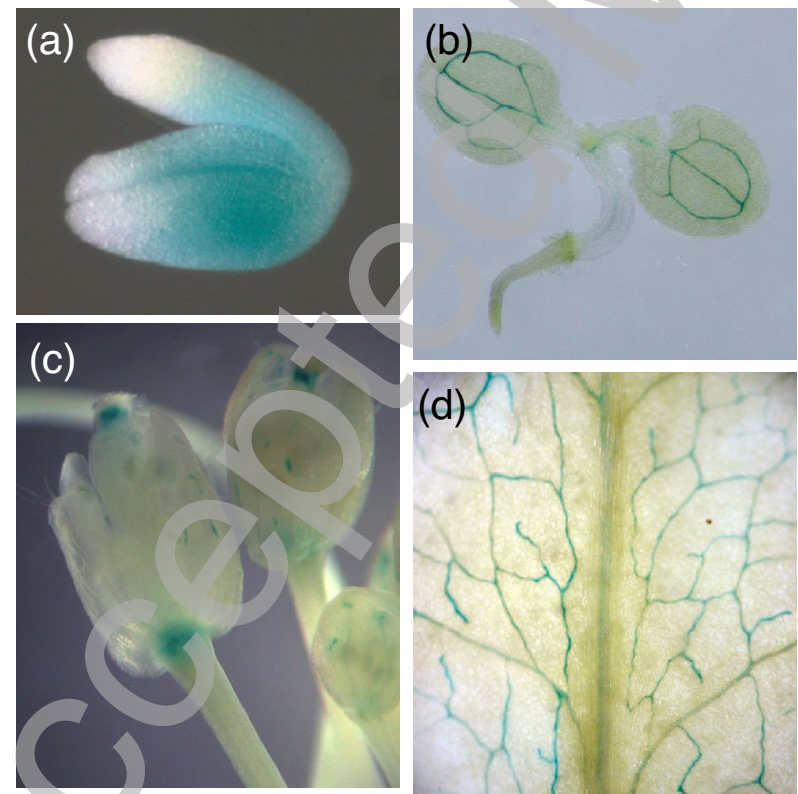

(d)

(e)

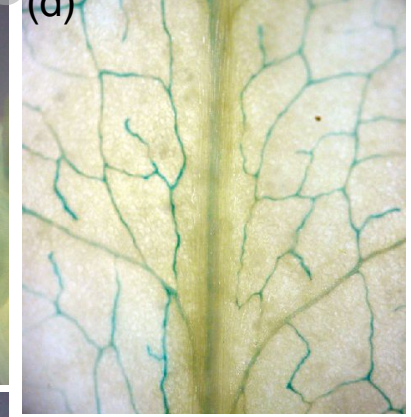

(f) 


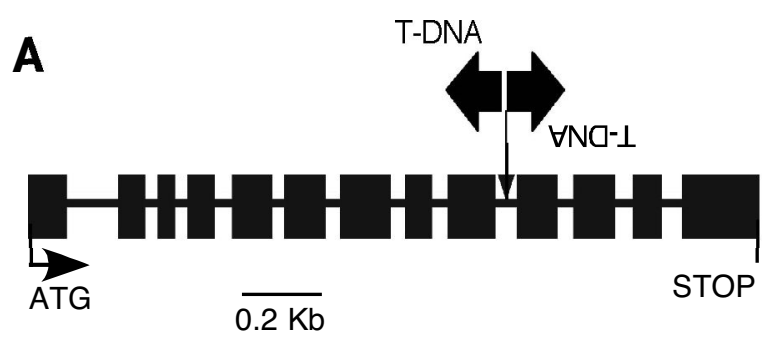

B
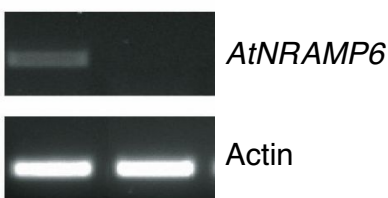

WT nramp6-1

C
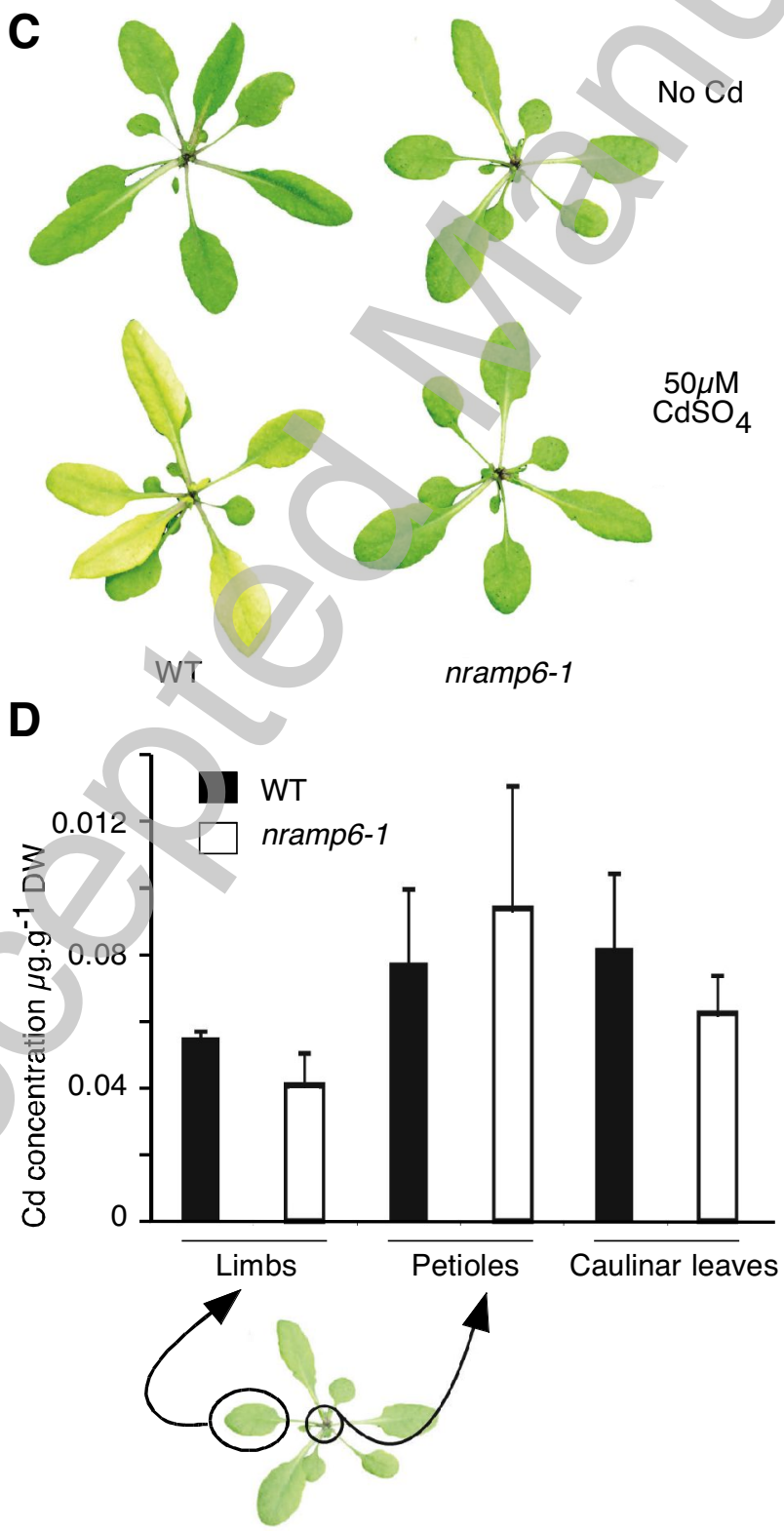

Licenced copy. Copying is not permitted, except with prior permission and as allowed by law. (c) 2009 The Authors Journal compilation (c) 2009 Portland Press Limited 
Biochemical Journal Immediate Publication. Published on 22 Jun 2009 as manuscript BJ20090655

A

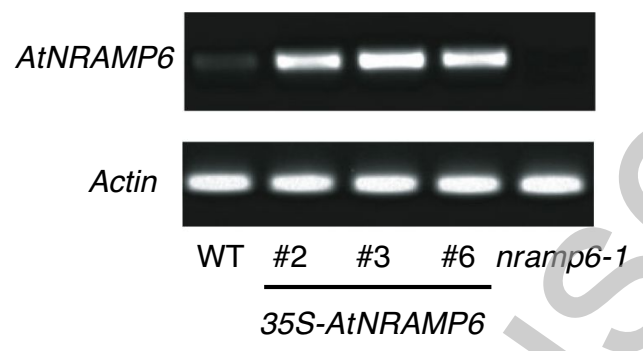

B
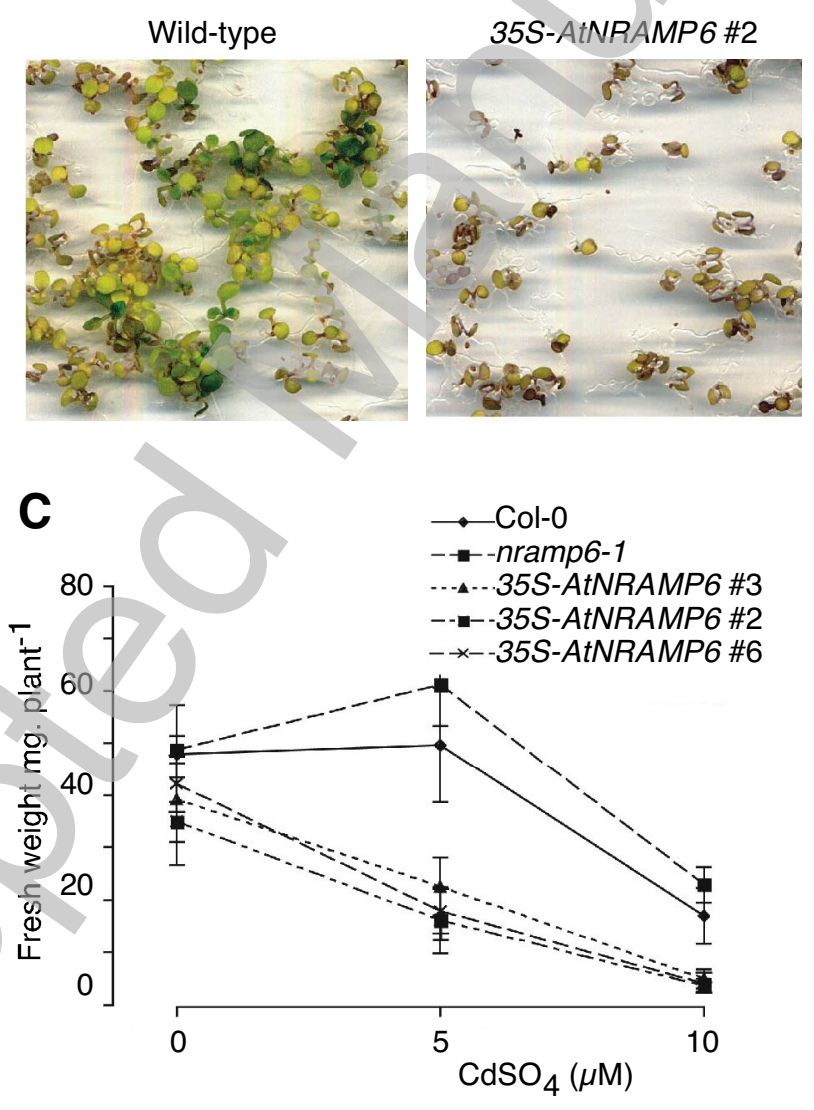

Licenced copy. Copying is not permitted, except with prior permission and as allowed by law. (C) 2009 The Authors Journal compilation (c) 2009 Portland Press Limited 
A

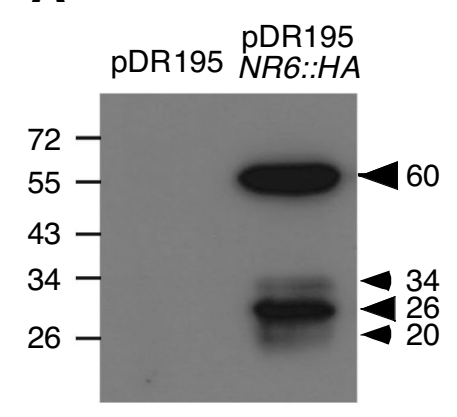

D

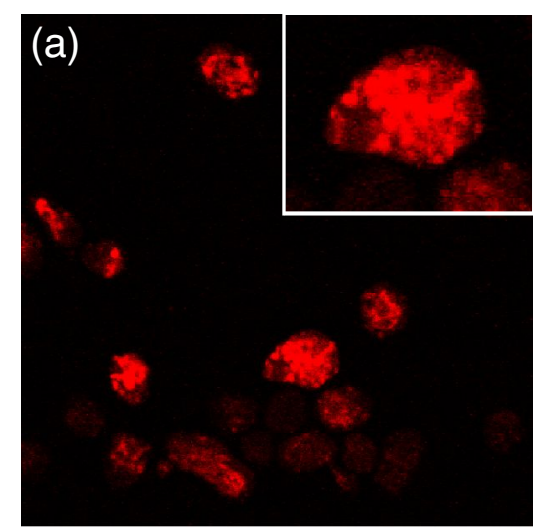

B

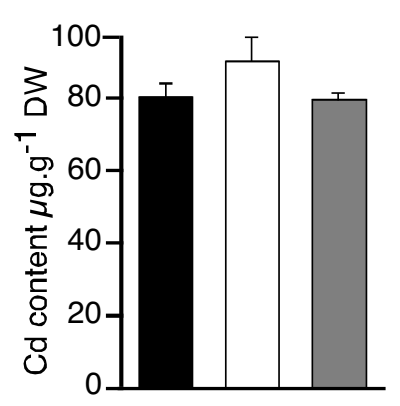

C $\frac{\text { Total }}{{ }_{\text {NR6 }}} \frac{\mathrm{M}}{\mathrm{NR6}} \frac{\mathrm{PM}}{\mathrm{NR6}}$ HA Pmat

Cox2 V-ATPase

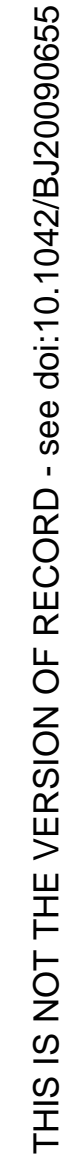

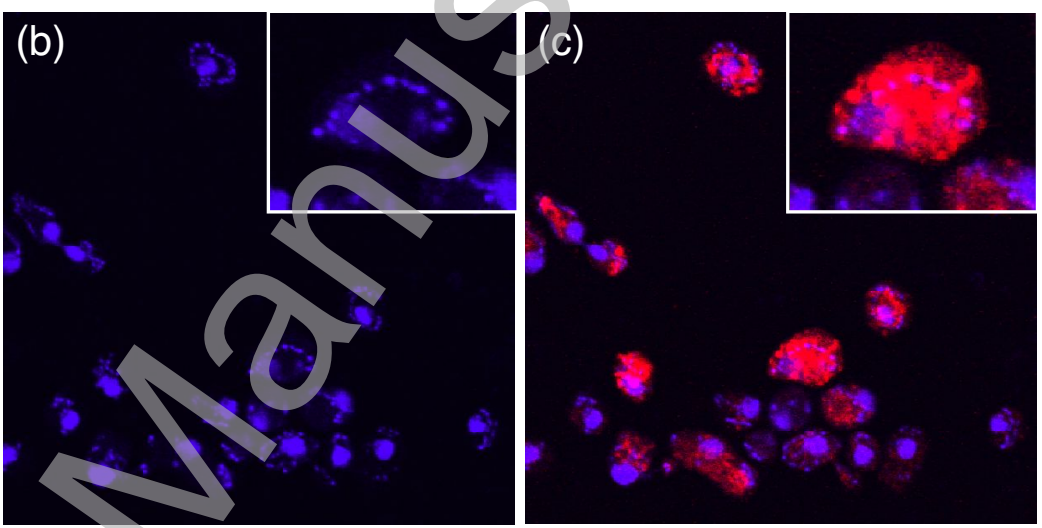

